\title{
Assessment of glycaemic control in stable type 2 black South African diabetics attending a peri-urban clinic
}

\author{
R T Erasmus, E Blanco Blanco, A B Okesina, Z Gqweta, T Matsha
}

\begin{abstract}
Summary
Glycaemic control was assessed in type 2 black diabetics attending the diabetic clinic at a peri-urban hospital. Baseline glycosylated haemoglobin levels were measured and a subsequent estimation was carried out in those patients who attended a follow-up consultation to see whether current recommended targets for glycosylated haemoglobin levels were being attained. Out of 708 patients, mean age 56.3 years, $14.7 \%$ were insulin treated and $85.3 \%$ were non-insulin-treated. Target values of $\mathrm{HbA1}<<7 \%$ were achieved in only $20.1 \%$ (142) of patients. Although mean glycosylated haemoglobin levels were significantly higher in females $(p=$ $0.03)$, the proportion of poorly controlled diabetics was similar in the two sexes. Patients whose HbA1c levels fell within the target values had diabetes of significantly shorter duration than those exhibiting poor control $(5.0+0.2$ vs $7.03+0.5$ years). Obesity was present in 562 patients
\end{abstract} $(79.4 \%)$. Target values were only achieved in $16.4 \%$ of non-obese and $21 \%$ of obese diabetics, with mean glycosylated haemoglobin levels being significantly higher $(p<0.05)$ in the former group $(10.3+0.4 \%$ vs $9.5+0.2 \%)$. Similar results were observed with respect to type of treatment, with only $14.4 \%$ of insulin-treated and $21 \%$ of non-insulin-treated diabetics achieving target values. The follow-up HbA1c estimation did not show any difference in the glycaemic control status of patients, with only $19.9 \%$ of them achieving the target values. Dietary advice (though minimal) seemed to have no impact on the metabolic control of our patients. These results suggest that glycaemic control was poor irrespective of sex, duration, BMI, educational status, dietary advice and type of treatment with recommended target values not being achieved in the majority of patients. Behavioural changes through health educational programmes need to be instituted with both patient and medical personnel being motivated to take this process forward.

Keywords: diabetes mellitus; black South Africans; glycaemic control
There is a growing body of evidence which suggests that the prevalence of diabetes mellitus in black South Africans has been steadily rising over the past two decades. ${ }^{1}$ Several reports have stressed the high morbidity and mortality from diabetes among blacks from Africa as well as from America. ${ }^{23}$ Indeed, deaths attributable to diabetes are twice as high in blacks than white Americans in both sexes. A recent study from Tanzania showed that the prognosis for diabetic patients in tropical Africa, even where facilities for care exist, is also much worse than for patients in developed countries. ${ }^{4}$ Post-mortem studies have indicated that infection and acute metabolic complications were common causes of death. ${ }^{56}$ Whilst several studies have examined the cause and course of black diabetics admitted to hospital wards, little is known about the glycaemic control of stable black African diabetics attending the out-patient clinics.

It is recognised that adequate glycaemic control is important in preventing both the acute and long-term complications of diabetes mellitus $^{7}$ and measurement of glycated haemoglobin is considered the gold standard method for assessing control status. ${ }^{8}$ The aim of the present study was to assess long-term glycaemic control in diabetic patients attending a black peri-urban community and examine some of the factors that may be associated with it, such as type of treatment, educational status, and dietary advice.

\section{Methods}

The research setting was the Umtata General Hospital, Umtata. This 1000-bed facility is the major referral centre for the former homeland of Transkei. The diabetic clinic is held once a week and all patients (Xhosa speaking) from the peripheral clinics, as well as within the hospital, are referred to it. Patients are usually seen at 3-monthly intervals and medical care is essentially free (including drugs) except for a small fee of six Rands (70 p) at each clinic visit. The study comprised 708 consecutive adult black type 2 diabetics attending the clinic over a one-year period. The case notes were reviewed and the data extracted included demographic data (sex, age, educational level), medical history (age at onset, duration of disease, family history), anthropometric data (weight, height), type of treatment, and related laboratory test results (fasting blood sugar, lipids). 
The present study consisted of a crosssectional observational analysis of metabolic control in 708 diabetic patients in which longterm glycaemic control was assessed by a baseline determination of glycosylated haemoglobin (HbA1c); and an observational cohort study using a second estimation of $\mathrm{HbA} 1 \mathrm{c}$ carried out in 281 patients who attended a follow-up consultation within a period of 3 to 12 months.

Glycaemic control was classified according to the HbA1c level as 'acceptable' $(<7 \%)$ or 'poor' $(>7 \%)$ in accordance with the target values recommended by the British Diabetic Association. ${ }^{9}$ Body mass index (BMI) was calculated using the Quetelet's index (kg per metre squared) and the cut off points used for diagnosis of obesity were 25 for females and 27 for males. HbA1c assays were performed using the IMx Glycated Haemoglobin assay package (Abbot, USA). This method is based on ion capture using a boronate affinity binding complex (normal range 4.4-6.4\%).

EDUCATIONAL STATUS

Patients were categorised into two main groups on the basis of education received (up to standard 7 or standard 8 and above). As the number of patients with tertiary education was relatively small, they were combined with those that had received secondary education.

DIABETES EDUCATION

Since the diabetic clinic did not operate a formal diabetes counselling programme at the time of this study, patients were only asked if they had received individually any form of dietary advice from the physician.

\section{STATISTICAL ANALYSIS}

Data were entered in a data base file using the dBase III program and further analysed using the EPI6 program to obtain and compare mean values of variables. Frequencies were expressed as percentages and means \pm SEM. Chi-square analysis was used to compare frequencies. Analysis of variance was used for continuous variables. The correlations between glycated haemoglobin levels and other intervening variables were tested using regression analysis. Statistical significance was accepted at $\mathrm{p}<0.05$.

\section{Results}

\section{PATIENTS}

There were 708 type 2 diabetics of mean age $56.3 \pm 0.44$ years; 513 were females $(72.5 \%)$ and 195 males $(27.5 \%)$. The duration of diabetes ranged from 0 to 36 years with a mean of $6.9 \pm 0.3$ years. The majority $(604,85.3 \%)$ were non-insulin-treated and $104(14.7 \%)$ were insulin-treated, both groups being similar with respect to mean age and sex (table 1). In total, 281 patients were followed up, 217 $(77.2 \%)$ females and $64(22.8 \%)$ males, with similar characteristics to the whole sample (mean age $56.0 \pm 0.7$ years, mean duration $7.4 \pm 0.34$ years, $18.5 \%$ insulin-treated and $81.5 \%$ non-insulin-treated.
Table 1 Overall clinical characteristics of patients

\begin{tabular}{llll}
\hline & Male & Female & Total \\
\hline$n$ & 195 & 513 & 708 \\
Age (years) & $55.4 \pm 0.9$ & $56.6 \pm 0.5$ & $56.3 \pm 0.4$ \\
Duration (years) & $7.0 \pm 0.5$ & $6.8 \pm 0.3$ & $6.9 \pm 0.3$ \\
Mean HbA1c (\%) & $9.3 \pm 0.2$ & $9.8 \pm 0.1$ & $9.6 \pm 0.1$ \\
BMI & $28.4 \pm 0.4$ & $35.2 \pm 0.3^{\star}$ & $31.2 \pm 0.3$ \\
Prevalence of obesity (\%) & 59.0 & $87.1^{\star}$ & 79.9 \\
Insulin-treated & 37 & $67^{\star}$ & 104 \\
Non-insulin-treated & 158 & $446^{\star}$ & 604 \\
\hline
\end{tabular}

${ }^{\star} \mathrm{p}<0.05$

Table 2 Frequency distriution of glycosylated haemoglobin values

\begin{tabular}{llll}
\hline HbA1c(\%) & Male & Female & Total (\%) \\
\hline$<7$ & 43 & 99 & $142(20.1)$ \\
$7.1-8.9$ & 55 & 118 & $173(24.4)$ \\
$9.0-10.9$ & 44 & 141 & $185(26.1)$ \\
$11.0-12.9$ & 35 & 91 & $126(17.8)$ \\
$>12.9$ & 18 & 64 & $82(11.6)$ \\
\hline
\end{tabular}

GLYCAEMIC CONTROL

At the beginning of the study the overall mean $\mathrm{HbA1c}$ was $9.6+0.1 \%$. Target values of $\mathrm{HbAlc}$ $<7 \%$ were achieved in only $20.1 \%$ of patients; 358 patients $(50.5 \%)$ had values between $7.1 \%$ and $10.9 \%$, while 208 patients (29.4\%) had values over $11 \%$ (table 2 ). Although mean glycosylated haemoglobin levels were significantly higher in female than male diabetics, the occurrence of poor glycaemic control was similar in the two sexes $(80.7 \%$ and $77.9 \%$, respectively) (table 1 ).

\section{OBESITY}

The overall occurrence of obesity in our study was $79.4 \%$ with a higher prevalence amongst females $(p<0.05)$. Both obese and non-obese patients exhibited poor metabolic control with higher mean glycosylated haemoglobin levels in the latter (table 3).

TYPE OF TREATMENT

Glycaemic control was similar in insulintreated and non-insulin-treated patients; $14.4 \%$ in the former and $21 \%$ in the latter group achieved target values for $\mathrm{HbAlc}$.

DURATION OF DIABETES

Patients with longer duration of diabetes exhibited poorer glycaemic control, and diabetics of more than 7 years duration had almost a two-fold increase in the occurrence of poor glycaemic control (Odds Ratio $=1.72$ ).

Table 3 Relationship of glycaemic control to sex, type of treatment, and obesity

\begin{tabular}{llll}
\hline Type of treatment & $\begin{array}{l}\text { Freq of } \\
\text { obesity (\%) }\end{array}$ & $\begin{array}{l}\text { Obese } \\
\text { HbA1c (\%) }\end{array}$ & $\begin{array}{l}\text { Non-obese } \\
\text { HbA1c (\%) }\end{array}$ \\
\hline Insulin-treated & 76.9 & $9.6 \pm 0.4$ & $10.7 \pm 0.7$ \\
Non-insulin-treated & 79.8 & $9.4 \pm 0.1$ & $10.3 \pm 0.3$ \\
Total & 79.4 & $9.6 \pm 0.1$ & $10.3 \pm 0.3$ \\
\hline
\end{tabular}


Table 4 Glycaemic control in follow-up patients; the difference between glycaemic control categories was $\mathrm{p}<0.05$ at both stages

\begin{tabular}{llllll}
\hline Stage of study & Glycaemic control & $n$ & Freq (\%) & Mean HbA1c (\%) & Mean duration (years) \\
\hline Beginning & good & 53 & 18.9 & $6.1 \pm 0.1$ & $5.3 \pm 0.7$ \\
& poor & 228 & 81.1 & $10.5 \pm 0.2$ & $7.8 \pm 0.4$ \\
Follow-up & good & 56 & 19.9 & $7.0 \pm 0.3$ & $5.7 \pm 0.8$ \\
& poor & 225 & 80.1 & $9.9 \pm 0.2$ & $7.8 \pm 0.4$ \\
\hline
\end{tabular}

EDUCATION

The educational status of $70.6 \%$ of patients was less than standard 8. However, similarly poor glycaemic control was observed in both groups.

Although 561 patients $(79.2 \%)$ received some form of dietary advice, the majority of these $(80.7 \%)$ did not attain recommended target values for $\mathrm{HbA} 1 \mathrm{c}$. A similar pattern was observed in patients who did not receive any dietary advice, with $76.7 \%$ not achieving the target values.

COHORT GLYCAEMIC CONTROL ANALYSIS

The comparison of the initial glycated haemoglobin level with a subsequent follow-up estimation performed in the 281 cases for whom such data were available, did not show any significant change with respect to glycaemic control status (table 4).

\section{Discussion}

Whilst morbidity and mortality data in black African diabetics are limited, there are reports that the course of the disease is much more severe in black than white diabetics. For example, various studies from America have highlighted poor glycaemic control in black diabetics. $^{3}$ This observation has also been made in diabetics from black Africa ${ }^{2}$ and other third-world countries. ${ }^{10}$

The results of this study showed that glycaemic control was poor in the majority of patients, irrespective of sex, treatment, or duration of diabetes. Our findings agree with the results of Weatherspoon ${ }^{11}$ and are also supported by some race-based studies which found not only a poorer glycaemic control in blacks but also reported that black women in particular had high HbA1c levels. ${ }^{12}{ }^{13}$ The poor metabolic control found at the beginning of

1 Levitt N, Katzenellenbongen J, Bradshaw D, Hoffman M, Bonnice $F$. The prevalence and identification of risk factors for NIDDM in urban Africans in Cape Town, South Africa. Diabetes Care 1993;16:601-7.

2 Castle WM, Wicks ACB. A follow up of 93 newly diagnosed African diabetics for 6 years. Diabetologia 1980;18:121-3.

3 US Department of Health and Human Services. Health United States, 1990. Public Health Service Center for Disease Control. National Center for Health Statistics, DHHS 1991; no PHS 91-1232.

4 McLarty DG, Kinabo L, Swai ABN. Diabetes in tropical Africa: a prospective study, 1981-7. II Course and prognosis. BMF 1990;300:1107-10.

5 Parson W, MacDonald FW, Shaper AG. African diabetics necropsied at Mulago Hospital, Kampula, Uganda 19571966. E Afr Med F 1969;45:89-99.

6 Bhook KD. A necropsy study of diabetes mellitus in Natal blacks. S Afr Med F 1976;50:1361-6.

7 Boulton A. Diabetes Control and Complications Trial: implications for diabetes care in the UK. Diabet Med 1993; 10:687. study and even after attendance at the diabetic clinic may reflect insufficient motivation, lack of knowledge, incorrect beliefs about diabetes, and particular cultural values, all of which are recognised to be potential barriers to improving diabetic care for blacks. ${ }^{14}$

Non-obese black diabetics from other parts of Africa have been reported to have poor glycaemic control but this has generally been attributed to pancreatic disease, as many such patients have extremely low BMI. ${ }^{15}$ It is unlikely that this was the case in our patients as the majority of the non-obese diabetics were neither thin nor were there clinical signs suggestive of pancreatic disease.

An interesting observation was that glycaemic control was completely independent of the educational level of our patients. Although the majority of patients had received some form of dietary advice, it was not assessed or regularly reinforced. It is possible that the lack of a regular and intensive diabetes education programme, due to the lack of health and nursing personnel in our facility, contributed to the poor metabolic control status even in those with better educational status. ${ }^{16}$ Dietary advice has been reported to improve serum lipid levels and reduce related long-term complications but not necessarily improve glycaemic control. D'Eramo-Melkus and colleagues ${ }^{17}$ found dietary advice to be helpful in improving metabolic control only when intense individual counselling leads to behavioural changes resulting in and promoting weight loss.

Our data imply that, even among clinic patients selected on variables that may be biased towards good adherence, target values were difficult to achieve. It is clear that urgent intervention strategies need to be designed and implemented to reduce the long-term complications of diabetes, especially at a time when healthcare costs are becoming prohibitively high. Behavioural changes through health educational programmes need to be instituted. Both patient and medical personnel need to be motivated to take this process forward. The $\mathrm{UKPDS}^{18}{ }^{19}$ has reported the beneficial effects of metformin in the metabolic control of overweight diabetics and emphasised the need for strict control of blood pressure. This message needs to be reinforced and implemented in the management of our patients and could be useful in improving their metabolic control.

8 Butler C, Peters J, Stott N. Glycated haemoglobin and metabolic control of diabetes mellitus: external versus locally established clinical targets for primary care. $B M \mathcal{F}$ 1995;310:784-8.

9 British Diabetic Association. Recommendation for the management of diabetes in primary care. London: BDA, 1993.

10 Erasmus RT, Sinha AK. Assessment of long term glycaemic control in diabetic patients attending Port Moresby General Hospital. PNG Med f 1995:38:17-20.

11 Weatherspoon LJ, Kumanyika SK, Ludlow R, Schatz D. Glycaemic control in a sample of black and white clinic patients with NIDDM. Diabetes Care 1994;17:1148-53.

12 Delamater AM, Albrecht DR, Postellon DC, Gutai JP. Racial differences in metabolic control of children and adolescents with type I diabetes mellitus. Diabetes Care 1991;14: $20-5$.

13 Eberhardt MS, Lackland DT, Wheeler FC, Teutsch SM. Glycaemic control in blacks and whites with diabetes in two South Carolina communities. Diabetes 1990;39(suppl 1): $205 \mathrm{~A}$ 
14 Anderson RM, Herman WH, Davis JM, Freedman RO, Funnel MM, Neighbors HW. Barriers to improving diabetes

5 Rao RH. Diabetes in the undernourished: coincidence or Rao RH. Diabetes in the undernourished
consequence? Endoc Rev 1988;9:67-87.

16 Campbell LV, Barth R, Gosper JK, Jupp JJ, Simons LA, Chisholm DJ. Impact of intensive educational approach to dietary change in NIDDM. Diabetes Care 1990;13:841-7.

17 D'Eramo-Melkus GA, Wylie-Rosett J, Hagan JA. Metabolic impact of education in NIDDM. Diabetes Care 1992;15: 864-9.
18 UKPDS 34. Effect of intensive blood glucose control and metformin on complications of overweight patients with type 2 diabetes. Lancet 1998;352:854-65.

19 UKPDS 38. Tight blood pressure control and risk macrovascular and microvascular complications in type 2 diabetes. BMF 1998;317:703-13.

\section{Medical Anniversary}

\section{Sir Patrick Manson, 3 October 1844}

(Sir) Patrick Manson (1844-1922) was born at Cromlet Hill, Aberdeenshire, the second son of a bank manager and laird. He was educated at Aberdeen University and became MD (1865) for a thesis on the internal carotid artery. He became a physician in Formosa and then Hong Kong. He added to scientific knowledge on filariasis due to Schistosoma mansoni, malaria, lung fluke and Diphyllobothrium mansoni (dog and cat worm). In later life he practised in Queen Anne Street, London, and gave tropical medicine lectures in several London hospitals. He earned the title, Father of tropical medicine, when he founded the London School of Tropical Medicine. He died on 9 April 1922 in County Galway. - DG Fames 